\title{
Influence of pre-symptomatic and symptomatic stages of Parkinson's disease and its treatment upon changes of variability of cardiac rhythm
}

\author{
M.L. Mamalyga' ${ }^{1}$ L.M. Mamalyga ${ }^{2}$ \\ ${ }^{1}$ Bakulev Scientific Center of Cardiovascular Surgery, Moscow, Russia \\ ${ }^{2}$ Department of Anatomy and Human and Animal Physiology of Institute Biology and Chemistry of \\ Moscow State University of Education, Moscow, Russia
}

\begin{abstract}
The aim of the study was to determine the influence of pre-symptomatic and symptomatic stages of Parkinson's disease and its treatment on the cardiac disorders in C57BL/6 mice.

Materials and methods. Investigations were carried out on C57BL/6 male mice. Degeneration of dopaminergic neurons were created by the neurotoxin. In freely moving animals in on line regime a 24-hour ECG recording using wireless telemetry system ML880B106 was conducted. After completing studies animals was injected L-dopa (a precursor of dopamine synthesis). All the animals underwent repeated study of HRV.

Results. The disbalance of autonomic heart regulation develops already in the pre-symptomatic stage of Parkinson's disease. The early symptomatic stage is accompanied by the aggravation of heart dysfunction due to the shift of the autonomic balance towards the increase of sympathetic and decrease of parasympathic effect on the heart. Coronary disorders concomitant to Parkinson's disease increase a risk of life threatening arrhythmia and sudden death syndrome not only in the early symptomatic stage but also in the pre-symptomatic stage.

Conclusions. L-dopa effectively restores the structure of heart rate and prevents the risk of life threatening arrhythmia only in the pre-symptomatic stage of disease.
\end{abstract}

Keywords: Parkinson's disease, autonomic heart regulation, life-threatening arrhythmia, L-dopa

\section{INTRODUCTION}

Parkinson's disease (PD) is one of the most wide spread, slowly progressing diseases determined by progressive degeneration of dopaminergic neurons of nigrostriatal system. These changes affects the brainstem nuclei and higher vegetative centers. They determine vegetative-visceral dysfunctions, especially by disturbing regulation of the cardiovascular system (1-3). Many cases of sudden cardiac death are reported in patients diagnosed with Parkinson's disease (4). Due to it, treatment of neurological symptoms in such patients without taking into consideration the cardiovascular system disorders can lead to cardiac dysfunction. It is known that the treatment of these patients using dopamine agonists increases the risk of cardiac failure $(5,6)$.
The question regarding the association of brain and heart disorders while using drugs based on dihydroxyphenylalanine (L-dopa) for treatment of patients with PD in different stages, still remains open.

The aim of the study was to determine the influence of pre-symptomatic and symptomatic stages of Parkinson's disease and its treatment on the cardiac disorders in C57BL/6 mice.

\section{EXPERIMENTAL SECTION}

\section{Materials and methods}

Investigations were carried out on $\mathrm{C} 57 \mathrm{BL} / 6$ male mice with body weight 25.0-30.0 g aged 2.5 months. Animals were kept under standard vivari- 
um conditions with free access to food and water. All studies were conducted in strict accordance with the basic bioethical "Rules of work with the use of experimental animals" and ARRIVE (Animal Research: Reporting of In Vivo Experiments) guidelines (7).

\section{Simulation of structural and functional changes of dopaminergic neurons of the nigrostriatal system (DNNS)}

To simulate pre-symptomatic stage (PSS) of PD 1-methyl-4-phenyl-1,2,3,6-tetrahydropyridine (MPTP, «Sigma», Germany) at a dose of $12 \mathrm{mg} / \mathrm{kg}$ with $30 \mu \mathrm{l}$ of normal saline was injected subcutaneously twice at intervals of 2 hours for 12 animals (8). To simulate early symptomatic stage (ESS), the same dose of neurotoxin was injected for 12 animals 4 times. In modeling the severe stage (SS) of DNNS, MPTP was administered at a dose of 18 $\mathrm{mg} / \mathrm{kg}$ for 15 animals four times, at intervals of 2 hours (9). The same volume of saline was injected for control animals (14 mice).

\section{Telemetric monitoring of electrocardiogram (ECG)}

Within 14 days after administration of the corresponding doses of neurotoxin or normal saline in freely moving animals in on line regime a 24 -hour ECG recording using wireless telemetry system ML880B106 («ADInstruments», Australia) was conducted. The system allows performing multi-day recording without contact with animals. A small $(2.5 \times 2 \times 0.8 \mathrm{~cm})$ transmitter (TR40BB), which was placed on top of the cage, transmitted the signal. Its electrodes were placed subcutaneously over the dorsal side of the body (between the shoulder blades) and were fixed to the greater pectoral muscle.

The operation was carried out before the injection of the neurotoxin, under general anesthesia with Zoletil and Rometar mixture (20 and $10 \mathrm{mg} /$ $\mathrm{kg}$ respectively) following aseptics and antiseptics rules. The postoperative period was 7 days.

ECG monitoring corresponded to I lead. Registration, recording and processing of ECG intervals were performed using the program LabChart 7 for mice. Measurement accuracy of R-R intervals was $1 \mathrm{msec}$, the sampling frequency $-1024 \mathrm{~Hz}$. In the study of heart rate variability (HRV) the following calculations were performed: 1) time-line analysis of heart rate: heart rate (HR), standard deviation $(\mathrm{SDNN})$, the square root of the sum of the squares of the difference between the values of successive pairs of intervals R-R (RMSSD); 2) spectral analysis: total spectral power (TP), spectral power of high- (HF), low- (LF) and extremely low frequency (VLF) components of variability, power spectrum in the high (HFnu) and low (LFnu) frequency in normalized units as well as the sympathetic-vagal index (LF/HF) and centralization index (IC). Furthermore, according to the ECG data, parameters of the left ventricular repolarization - QT, QTc, TpcakTend - were analyzed.

After completing studies in animals with PSS and ESS of PD Madopar-125 («Hoffmann-La Roche», Switzerland) was injected during 10 days. Madopar-125 contains L-dopa (a precursor of dopamine synthesis) and bensrazid (inhibitor of peripheral decarboxylation of L-dopa). The medicine was administered intraperitoneally in a form of freshly prepared aqueous suspension at a dose of $25.5 \mathrm{mg} / \mathrm{kg}$ of body weight (by L-dopa). Control animals received the corresponding volumes of normal saline. All the animals underwent repeated study of HRV.

Statistical analyses were performed using Statistics 6.0 software. The test values were determined as the arithmetic mean and standard error of the mean. The significance of differences between mean values was evaluated by Student's t-test.

\section{RESULTS AND DISCUSSION}

Numerous studies of PD are suggesting that the symptomatology of this neurodegenerative disorder may become manifest only 2-3 decades after the start of the disease, when more than $50-60 \%$ of dopaminergic neurons of the substantia nigra are lost. Because of the high neuroplasticity resources of the nigrostriatal system in early stages of neurodegenerative disorders, dopaminergic insufficiency can be compensated and so, clinical manifestation of PD are delayed (10). However, these disorders affect the autonomic centers $(11,12)$. Hence, the question about the contingency of compensatory brain capacity with the mechanisms of autonomic regulation of the heart at different stages of PD arises. Due to the lack of consensus about the peculiarities of non-motor symptoms manifestations in the different stages of PD, their treatment is often ignored (11). To resolve this issue there should be performed not only clinical, but also experimental studies on adequate models of pre-symptomatic and symptomatic stages of PD in C57BL/6 mice (8). In this regard, we conducted the analysis of heart rate regulation in C57BL/6 mice pre-symptomatic (PSS), early symptomatic (ESS) and severe 
(SS) stages of dopaminergic neurons degeneration (DDN) of nigrostriatal system (model of Parkinson's disease) before and after treatment with L-dopa (Figure 1).

In pre-symptomatic, early symptomatic and severe stages of DDN different changes in the sympathetic-vagal index were revealed (Table 1). This suggests that in the progression of DDN are observed different variants of the neurovegetative regulation of the heart. Motor behavior disorders don't appear in pre-symptomatic PD mice models, but the degenerative pathology is suggested by the reduction in the number of dopaminergic axons in striatum and dopamine concentration $(8,13)$. More-

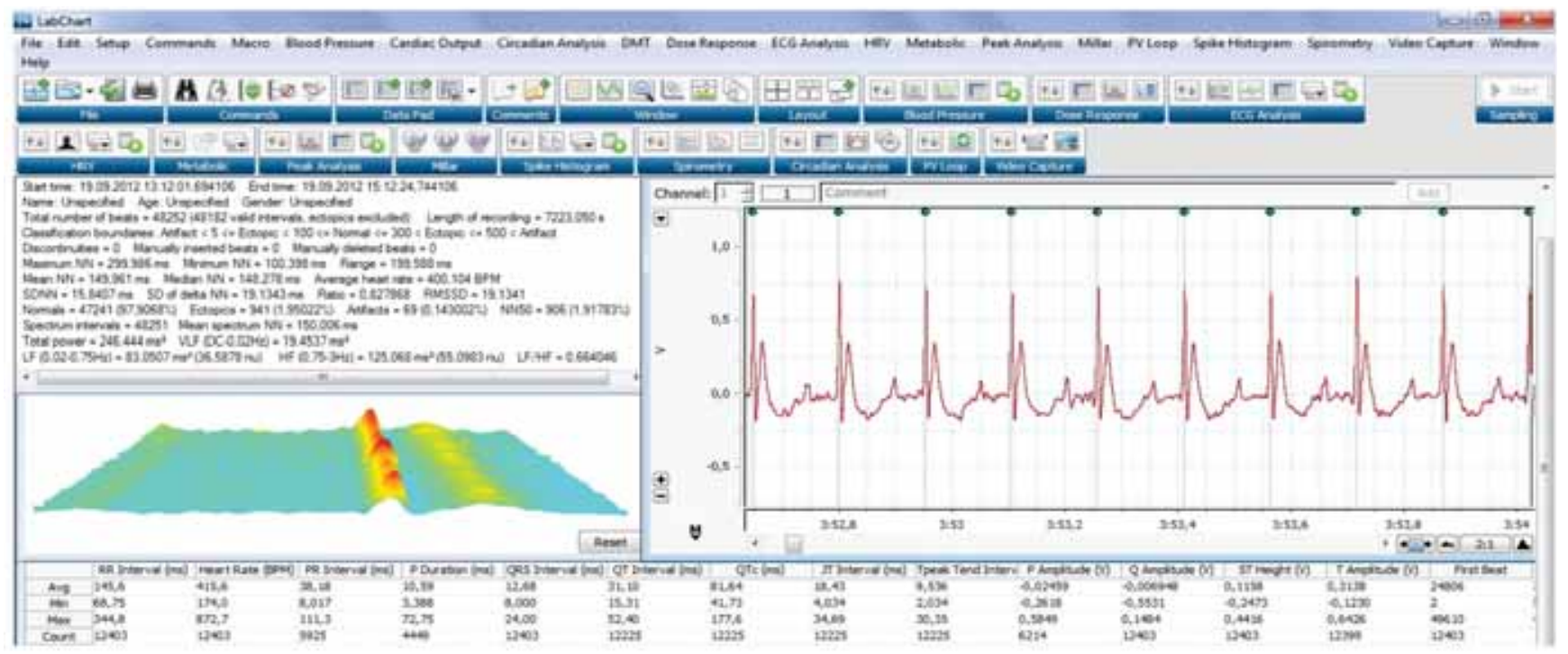

FIGURE 1. Telemetric online ECG registration with analysis of intervals duration and variability of cardiac rate in C57BL/6 mice with early symptomatic stage of dopaminergic neurons degeneration

TABLE 1. Change of variability of cardiac rate in different stages of dopaminergic neurons degeneration as well as in activation of dopaminergic mechanisms

\begin{tabular}{|c|c|c|c|c|c|c|}
\hline \multirow{2}{*}{ HRV } & \multirow{2}{*}{ Control $n=14$} & \multirow{2}{*}{$\begin{array}{c}\text { PS } \\
n=12\end{array}$} & \multirow{2}{*}{$\begin{array}{c}\text { ESS } \\
n=12\end{array}$} & \multirow{2}{*}{$\begin{array}{c}\text { SS } \\
n=15\end{array}$} & \multicolumn{2}{|c|}{ L-dopa } \\
\hline & & & & & PS $n=12$ & ESS $n=12$ \\
\hline $\mathrm{HR}$ & $507 \pm 44,1$ & $527 \pm 47,3$ & $499 \pm 31,9$ & $562 \pm 72,5$ & $466 \pm 41,4$ & $470 \pm 43,2$ \\
\hline RMSSD & $18 \pm 1,49$ & $\begin{array}{c}33,6 \pm 2,85 \\
P<0,001\end{array}$ & $\begin{array}{r}10 \pm 0,84 \\
P<0,001 \\
\end{array}$ & $\begin{array}{l}8,4 \pm 0,76 \\
P<0,001\end{array}$ & $\begin{array}{c}23,7 \pm 1,75 \\
P<0,05\end{array}$ & $\begin{array}{l}14 \pm 1,01 \\
P<0,05\end{array}$ \\
\hline SDNN & $91 \pm 7,46$ & $86,4 \pm 7,13$ & $\begin{array}{l}59 \pm 5,71 \\
P<0,01\end{array}$ & $\begin{array}{l}42 \pm 4,12 \\
P<0,001\end{array}$ & $96 \pm 9,01$ & $82 \pm 6,97$ \\
\hline $\mathrm{TP}, \mathrm{MC}^{2}$ & $166 \pm 11,32$ & $\begin{array}{c}234 \pm 16,8 \\
P<0,01 \\
\end{array}$ & $175 \pm 13,1$ & $\begin{array}{l}82 \pm 6,89 \\
P<0,001\end{array}$ & $190 \pm 15,22$ & $186 \pm 14,7$ \\
\hline$H F, M C^{2}$ & $111 \pm 7,2$ & $\begin{array}{c}183 \pm 15,5 \\
P<0,01\end{array}$ & $\begin{array}{l}70 \pm 4,55 \\
P<0,01\end{array}$ & $\begin{array}{l}24 \pm 2,28 \\
P<0,001\end{array}$ & $\begin{array}{c}132 \pm 5,43 \\
P<0,05\end{array}$ & $\begin{array}{l}84 \pm 6,5 \\
P<0,05 \\
\end{array}$ \\
\hline$L F, M C^{2}$ & $24 \pm 2,02$ & $25 \pm 1,95$ & $\begin{array}{l}58 \pm 4,45 \\
P<0,001\end{array}$ & $\begin{array}{l}7,7 \pm 0,57 \\
P<0,001 \\
\end{array}$ & $27 \pm 1,94$ & $\begin{array}{l}42 \pm 3,86 \\
P<0,01 \\
\end{array}$ \\
\hline $\mathrm{VLF}, \mathrm{MC}^{2}$ & $31 \pm 2,34$ & $32 \pm 2,91$ & $\begin{array}{c}52 \pm 3,9 \\
P<0,001 \\
\end{array}$ & $\begin{array}{l}51 \pm 4,69 \\
P<0,01\end{array}$ & $32 \pm 2,77$ & $\begin{array}{c}60 \pm 5,75 \\
P<0,001\end{array}$ \\
\hline$H F, \%$ & $67 \pm 5,91$ & $76 \pm 6,23$ & $\begin{array}{l}38 \pm 3,34 \\
P<0,01\end{array}$ & $\begin{array}{l}29 \pm 2,51 \\
P<0,001\end{array}$ & $68,9 \pm 6,01$ & $\begin{array}{c}45,1 \pm 3,42 \\
P<0,01 \\
\end{array}$ \\
\hline$L F, \%$ & $14,5 \pm 1,16$ & $\begin{array}{c}10,4 \pm 0,96 \\
P<0,05\end{array}$ & $\begin{array}{r}32 \pm 2,43 \\
P<0,001\end{array}$ & $\begin{array}{l}8,5 \pm 0,72 \\
P<0,001\end{array}$ & $14,2 \pm 1,28$ & $\begin{array}{c}22,6 \pm 2,05 \\
P<0,01\end{array}$ \\
\hline VLF, \% & $18,7 \pm 1,72$ & $\begin{array}{c}13,3 \pm 1,08 \\
P<0,05\end{array}$ & $\begin{array}{l}29 \pm 2,09 \\
P<0,01\end{array}$ & $\begin{array}{l}62 \pm 5,33 \\
P<0,001\end{array}$ & $16,8 \pm 1,28$ & $\begin{array}{c}32,2 \pm 3,02 \\
P<0,01 \\
\end{array}$ \\
\hline $\mathrm{HF}, \mathrm{nu}$ & $82 \pm 6,41$ & $88 \pm 7,78$ & $\begin{array}{l}54 \pm 4,91 \\
P<0,01\end{array}$ & $77 \pm 6,62$ & $82,9 \pm 7,22$ & $66,7 \pm 4,73$ \\
\hline LF, nu & $17,8 \pm 1,14$ & $\begin{array}{l}12 \pm 0,89 \\
P<0,05\end{array}$ & $\begin{array}{r}45 \pm 3,83 \\
P<0,001 \\
\end{array}$ & $22 \pm 2,06$ & $17,1 \pm 1,32$ & $\begin{array}{l}33,3 \pm 2,9 \\
P<0,001\end{array}$ \\
\hline $\mathrm{LF} / \mathrm{HF}$ & $0,22 \pm 0,02$ & $\begin{array}{c}0,14 \pm 0,01 \\
P<0,05\end{array}$ & $\begin{array}{c}0,83 \pm 0,08 \\
P<0,001 \\
\end{array}$ & $\begin{array}{c}0,33 \pm 0,02 \\
P<0,05\end{array}$ & $0,2 \pm 0,01$ & $\begin{array}{l}0,5 \pm 0,04 \\
P<0,001\end{array}$ \\
\hline IC & $0,50 \pm 0,03$ & $\begin{array}{c}0,31 \pm 0,02 \\
P<0,01\end{array}$ & $\begin{array}{l}1,57 \pm 0,14 \\
P<0,001 \\
\end{array}$ & $\begin{array}{c}2,47 \pm 0,22 \\
P<0,001\end{array}$ & $0,45 \pm 0,04$ & $\begin{array}{l}1,2 \pm 0,11 \\
P<0,001\end{array}$ \\
\hline
\end{tabular}


over, the decrease in the number of neurons in substantia nigra and increase of dopamine content in the preserved cells reflects a compensatory increase in its synthesis.

The study of daily ECG recordings in these animals showed an increase of the total power of the spectrum, an increase of the power of HF-waves, as well as reducing of the power of LF-waves. Since the activity of HF-waves is considered to be criterion of parasympathetic influences on the heart, and LF-waves - of sympathetic, a statistically significant increase of $\mathrm{HFms}^{2}$ and decrease of LF\%, LFnu and $\mathrm{VLF} \%$ testifies to appearance of vagotonia in the DDN pre-symptomatic stage, testifies for the predominance of parasympathetic over sympathetic influence. Decrease of indices LF/HF, IC and increase of RMSSD are also indicative of the parasympathetic tone strengthening.

Nowadays the protective effect of vagal activity is well known. Thus vagotonia is accompanied by increased coronary perfusion, myocardial electrical stabilization, whereas the decrease of vagal activity correlates with increased risk of sudden cardiac death. Therefore, reduction of LF/HF index, as well as an increase of the total power of the spectrum at pre-symptomatic DDN stage reflects a compensatory response of the autonomic nervous system. Other authors deem the same $(3,14)$. However, detected increase of QT and QTc (Table 2) at this time testifies that compensatory mechanisms fail to prevent a high risk of life-threatening arrhythmias occurrence.

While investigating ESS of PD in mice, as in the PSS, the authors of this model found the compensatory remodeling of dopaminergic neurons $(8,13)$. However, in ESS disorders of motor behaviour are more pronounced than in PSS. This is due to the decrease in the concentration of dopamine and the number of dopaminergic axons in the striatum. At that, preserved neurons of substantia nigra increase dopamine synthesis.

Despite the compensatory potential of neurons, dysfunction of the autonomic regulation of the heart, caused by pronounced predominance of sympathetic influences above the parasympathetic ones, occurs in ESS of DDN. A significant increase of the absolute and relative power of the LF-waves and decrease of HF-waves is representative of that. At the same time sympathetic-vagal index is increased compared with controls 3.8-fold, and the total effect of vegetative regulation of blood circulation (SDNN) is reduced by $35 \%$.

Thus, in ESS of DDN combination of sympathetic and parasympathetic dysfunction of the autonomous regulation of the heart occurs, which is accompanied by a shift of the vegetative balance towards increasing of the sympathetic effects on the heart. Disorganization of vegetative mechanisms may lead to a worsening of cardiac pathology. Significant increase of QT and QTc intervals (Table 2), which is a predictor of fatal ventricular arrhythmias occurrence, confirms it. Received results are consistent with clinical data as for disorders of HRV in the early manifestations of extrapyramidal disorders $(1,14,15)$. One of the reasons of such disorder can be caused by dopaminergic dysfunction of the higher vegetative centers of the hypothalamus, occurring in PD $(12,16)$. It cannot be ruled out at MPTP-induced model of nigrostriatal dopaminergic insufficiency.

The size of ST-segment amplitude allowed excluding ischemic damage, and absence of the changes of $\mathrm{PR}$ and QRS intervals and $\mathrm{P}$ wave duration testifies to normal conduction in the atria and the ventricles in PSS and ESS of DDN. However, the reduction of HRV in early symptomatic stage, accompanied by 3 -fold IC increase, testifies to an increase of regulation systems exertion and decrease of their functional capacities.

TABLE 2. ECG parameters in different stages of dopaminergic neurons degeneration as well as in activation of dopaminergic mechanisms

\begin{tabular}{|c|c|c|c|c|c|c|}
\hline \multirow{2}{*}{ ECG } & \multirow{2}{*}{ Control $n=14$} & \multirow{2}{*}{$\begin{array}{l}\text { PSS } \\
n=12\end{array}$} & \multirow{2}{*}{ ESS $n=12$} & \multirow{2}{*}{$\begin{array}{c}\text { SS } \\
n=15\end{array}$} & \multicolumn{2}{|c|}{ L-dopa } \\
\hline & & & & & PSS $n=12$ & ESS $n=12$ \\
\hline $\mathrm{RR}, \mathrm{MC}$ & $118 \pm 9,9$ & $113 \pm 8,4$ & $120 \pm 10,4$ & $106 \pm 10,1$ & $107 \pm 9,53$ & $132 \pm 10,7$ \\
\hline $\mathrm{PR}, \mathrm{MC}$ & $33 \pm 2,54$ & $37 \pm 2,47$ & $30 \pm 2,77$ & $28 \pm 2,44$ & $34 \pm 2,61$ & $35 \pm 3,18$ \\
\hline $\mathrm{P}, \mathrm{MC}$ & $12 \pm 0,89$ & $14 \pm 0,75$ & $11 \pm 0,71$ & $11 \pm 0,83$ & $14 \pm 0,88$ & $14 \pm 0,76$ \\
\hline QRS, MC & $13 \pm 1,05$ & $12 \pm 0,77$ & $15 \pm 1,21$ & $14 \pm 0,91$ & $12 \pm 1,04$ & $14 \pm 1,01$ \\
\hline $\mathrm{QT}, \mathrm{MC}$ & $29 \pm 2,13$ & $\begin{array}{l}36 \pm 2,31 \\
P<0,05\end{array}$ & $\begin{array}{l}40 \pm 3,08 \\
P<0,05\end{array}$ & $\begin{array}{l}41 \pm 3,11 \\
P<0,01\end{array}$ & $31 \pm 2,96$ & $\begin{array}{l}38 \pm 2,81 \\
P<0,05\end{array}$ \\
\hline QTC, MC & $85 \pm 6,21$ & $\begin{array}{c}106 \pm 7,11 \\
P<0,05\end{array}$ & $\begin{array}{l}119 \pm 9,0 \\
P<0,01\end{array}$ & $125 \pm 8,51$ & $95 \pm 7,42$ & $\begin{array}{c}105 \pm 6,67 \\
P<0,05\end{array}$ \\
\hline $\begin{array}{l}\text { Tpeak } \\
\text { Tend, Mc } \\
\end{array}$ & $8,7 \pm 0,5$ & $9,9 \pm 0,77$ & $9,1 \pm 0,64$ & $10,5 \pm 0,89$ & $9,7 \pm 0,74$ & $9,9 \pm 0,83$ \\
\hline $\mathrm{ST}, \mathrm{MB}$ & $-0,12 \pm 0,01$ & $-0,14 \pm 0,01$ & $-0,11 \pm 0,009$ & $-0,12 \pm 0,01$ & $-0,14 \pm 0,01$ & $-0,13 \pm 0,01$ \\
\hline
\end{tabular}


Analysis of the data concerning direct effect of neurotoxin upon the sympathetic innervation of the heart in MPTP-induced PD model, suggests that high doses (about $100 \mathrm{mg} / \mathrm{kg}$ ) of the medicine reduce myocytes response to norepinephrine and its content in the heart $(17,18)$. MPTP doses used in our study did not change the level of norepinephrine and dopamine in the heart and adrenal glands (19). The increase of absolute and relative power of LF- and VLF-waves on ESS of BP reflects the high sympathetic activity, indirectly indicating that the doses of MPTP used are not causing cardiac sympathectomy.

Severe degeneration of dopaminergic neurons is accompanied by a pronounced decline of all HRV spectra power, as well by the imbalance between the sympathetic and parasympathetic systems. A significant reduction of the total spectrum power and its components $\left(\mathrm{LFms}^{2}, \mathrm{HFms}^{2}\right)$ not only in comparison with the control, but also with the ESS, testifies to low compensatory reserve of neurocardial regulation systems of heart rhythm in severe stage of DDN. A similar decrease in HRV (SDNN) and the power of the parasympathetic system (RMSSD) was found not only in the spectral but also in the statistical analysis. An important peculiarity of the SS of DDN as compared to the ESS is not only a significant reduction of the absolute power of LF-waves but its fraction in the total structure of the spectrum (LF\%). The reduction of parasympathetic and sympathetic systems activity may be a cause of neuro-cardiovascular instability which may manifest in human patients diagnosed with PD with heart arrythmias, bradycardia and vasovagal syncope (20).

Another peculiarity of SS of DDN is maintaining a high level of IC at decreasing of HRV. This indicates the increased activity of vasomotor center and humoral regulation of cardiac function. QT, QTc intervals elongation combined with a significant reduction in the total HRV is prognostic unfavorable factor for development of life-threatening arrhythmias, even without organic heart pathology. Besides that, individual episodes of atrioventricular block 2:1 and reducing of the heart rate were detected in animals with SS of DDN. According to the European recommendations on cardiac pacing and cardiac resynchronization therapy (2013), a combination of Mobitz type II heart block with QTc interval elongation is considered to be life-threatening situation.

Thus, the analysis of the received results showed that the disorder of HRV structure indices occur not only in the early and severe stages of progressive neuronal degeneration of the nigrostriatal system, but also in pre-symptomatic stage of the disease. It is therefore of interest to study the regulation of cardiac functioning in the treatment of DDN.

Replacement therapy with medicines the base of which the levorotatory isomer of dihydroxyphenylalanine forms (L-dopa), plays the leading role in this issue. It is the precursor of dopamine, which is particularly effective completes its deficiency in the nigrostriatal system in Parkinson's disease.

Administration of L-dopa for animals with pre-symptomatic and ESS of DDN unequally affects the HRV (Table 1). Thus, normalization of HRV occurs in animals with PSS, while in animals with ESS this is not observed. At that increase of the absolute and relative power of LF-waves and decrease of HF-waves is preserved. This is accompanied by an increase of LF/HF and IC indices, as well as duration of QT and QTc intervals (Table 2). It should be noted that after administration of L-dopa for animals with ESS increase of sympathetic influence on heart was significantly lower than before treatment. A similar conclusion can be drawn regarding the sympathetic-vagal index.

The final results are consistent with the clinical concept that visceral autonomic dysfunctions are an important element of the pathogenesis of PD $(1,12)$. Studies have shown that compensatory mechanisms detected during pre-symptomatic and early symptomatic stages of PD $(8,13)$ do not prevent disorders of the autonomic regulation of the heart. Despite peculiarities of their manifestations depending on the severity of dopaminergic deficiency, it is obvious that cardiac dysfunctions associated with DDN, increase the risk of life-threatening arrhythmias and sudden cardiac death not only in the early symptomatic, but in pre-symptomatic stage of the disease.

The use of L-dopa effectively restores HRV structure and prevents the risk of life-threatening arrhythmias only in pre-symptomatic stage of the disease. Therefore, therapeutic interventions in this period will allow maximal delaying the onset of concomitant cardiac pathology which aggravates neurological condition.

\section{CONCLUSIONS}

Imbalance of autonomous heart regulation and hightened risk of fatal ventricular arrhythmias occurs not only in early and severe stage of nigrostriatal system's dopaminergic neurons degeneration, but in pre-symptomatic stage of the disease as well. Increase of dopaminergic system's activity with the help of precursor of dopamine synthesis (L-dopa) effectively restores the structure of cardiac rhythm 
variability only in pre-symptomatic disorders of nigrostriatal system's dopaminergic neurons.

\section{Acknowledgments}

No funding or financial support was obtained for this study.

Author Contributions: Maxim Mamalyga designed the studies, recorded ECG, analysis and interpreted data, wrote multiple drafts of the manu- script and submitted the manuscript. Leonid Mamalyga was involved in the protocol development and implementation, was arranged all required materials for the accomplishment of this research and reviewed the article.

Conflicts of interest: The authors declare no conflict of interest.

\section{REFERENCES}

1. Haapaniemi T. Autonomic dysfunction in Parkinson's disease and its correlates to medication and dopamine transporter binding. University of Oulu, 2001, 127 p. (Google Scholar) (CrossRef)

2. Pursiainen V. Autonomic dysfunction in early and advanced Parkinson's disease. Universitatis Ouluensis, Oulu, 2007. (Google Scholar)

3. Haapaniemi T.H., Pursiainen V., Korpelainen J.T., Huikuri H.V., Sotaniemi K.A., Myllylä V.V. Ambulatory ECG and analysis of heart rate variability in Parkinson's disease. J. Neurol. Neurosurg. Psychiatry 2001, 70, 305-310. (CrossRef) (PubMed)

4. Deguchi K., Sasaki I., Tsukaguchi M., Kamoda M., Touge T., Takeuchi H., Kuriyama S. Abnormalities of rate-corrected QT intervals in Parkinson's disease - a comparison with multiple system atrophy and progressive supranuclear palsy. J. of the Neurological. Sciences 2002; 199, 31-37. (CrossRef) (PubMed)

5. Mokhles M.M., Trifiro G., Dieleman J.P., Haag, M.D., van Soest E.M., Verhamme K.M., Mazzaglia G., Herings R., Luise Cd., Ross D., at al. The risk of new onset heart failure associated with dopamine agonist use in Parkinson's disease. Pharmacological Research 2012, 65, 358-364. (CrossRef) (PubMed)

6. Oeda T., Masaki M., Yamamoto K., Mizuta E., Kitagawa N., Isono T., Taniguchi S., Doi K., Yaku H., Yutani C., at al. High risk factors for valvular heart disease from dopamine agonists in patients with Parkinson's disease. J. Neural. Transm 2009, 116, 171-178. (CrossRef) (PubMed)

7. Kilkenny C., Brown W.J., Cuthill I.C., Emerson M., Altman D.G. Animal Research: Reporting In Vivo Experiments: The ARRIVE guidelines. J Gene Med. 2010, doi: 10.1002/jgm.1473. (CrossRef) (PubMed)

8. Ugrumov M.V., Khaindrava V.G., Kozina E.A., Kucheryanu, V.G., Bocharov E.V.; Kryzhanovsky G.N., Kudrin V.S., Narkevich V.B., Klodt P.M., Rayevsky K.S., at al. Modeling of presymptomatic and symptomatic stages of parkinsonism in mice. Neuroscience 2011, 181, 175-188. (CrossRef) (PubMed)

9. Jackson-Lewis V., Przedborski S. Protocol for the MPTP mouse model of Parkinson's disease. Nat. Protoc. 2007, 2, 141-151 (CrossRef) (PubMed)

10. Ugrumov M.V. Development of preclinical diagnosis and preventive treatment of neurodegenerative diseases. Zh. Nevrol. Psikhiat.r Im S S Korsakova 2015, 115, 4-14. (CrossRef) (PubMed)

11. Bhidayasiri R., Truong D.D. Therapeutic strategies for nonmotor symptoms in early Parkinson's disease: the case for a higher priority

and stronger evidence. Parkinsonism Relat. Disord. 2012, 18, 110-113. (CrossRef) (PubMed)

12. Politis M., Piccini P., Pavese N., Koh S.B., Brooks D.J. Evidence of dopamine dysfunction in the hypothalamus of patients with Parkinson's disease: An in vivo 11C-raclopride PET study. Experimental Neurology 2008, 214, 112-116. (CrossRef) (PubMed)

13. Gibbons R.J., Balady G.J., Bricker J.T. Guideline Update for Exercise Testing A Report of the American College of Cardiology. American Heart Association Task Force on Practice Guidelines (Committee on Exercise Testing) ACC/AHA Practice Guidelines. USA, 2002, 59 p. (Google Scholar)

14. Oka H., Mochio S., Onouchi K. Cardiovascular dysautonomia in de novo Parkinson's disease. Neurol. Sci. 2006, 241, 59-65. (CrossRef) (PubMed)

15. Devos D., Kroumova M., Bordet R., Vodougnon H., Guieu J.D., Libersa C., Destee A. Heart rate variability and Parkinson's disease severity. J. Neural. Transm. 2003, 110, 997-1011 (CrossRef) (PubMed)

16. Rieu I., Boirie Y., Morio B., Derost P., Ulla M., Marques A., Debilly B., Bannier S., Durif F. The Idiopathic Parkinson's disease: A metabolic disease? Rev. Neurol. (Paris) 2010, 166, 822-828. (Google Scholar) (CrossRef)

17. Algeri S., Ainbrosio S., Garofalo P., Gerli P. Peripheral effects of 1-methyl- 4-phenyl-I,2,3,6-tetrahydropyridine (MPTP) and its main metabolite l-methyl-4-phenylpyridinium ion (MPP+) in the rat. European Journal of Pharmacology 1987, 141, 309-331. (CrossRef) (PubMed)

18. Ren J., Porter J.E., Wold L.E., Aberle N.S., Muralikrishnan D., Haselton J.R. Depressed contractile function and adrenergic responsiveness of cardiac myocytes in an experimental model of Parkinson disease, the MPTP-treated mouse. Neurobiology of Aging. 2004, 25, 131-138. (CrossRef) (PubMed)

19. Ambrosio S., Blesa R., Mintenig G.M., Palacios-Araus L., Mahy N., Gual A. Acute effects of I-methyl-4-phenyl-1,2,3,6-tetrahydropyridine (MPTP) on catecholamines in heart, adrenal gland, retina and caudate nucleus of the cat. Toxicology Letters. 1988, 44, 1-6. (CrossRef) (PubMed)

20. Tishkova I.G., Preobrazhenskaya I.S. Analysis of heart rate variability in patients with dementia with Lewy bodies and Parkinson's disease. Nevrol. Neuropsychiatrist. Psychosocial. 2011, 1, 46-51. (Google Scholar) (CrossRef) 